\title{
“LA POESÍA, AUNQUE NO SEA CAPAZ DE DERRIBAR UN RÉGIMEN, NO DEJA DE TRANSFORMAR EL MUNDO": ENCUENTRO CON ÁNGEL GONZÁLEZ
}

\author{
PABLO CARRIEDO CASTRO \\ (Investigador. León)
}

\section{Preámbulo}

La obra poética de Ángel González (Palabra sobre palabra. Seix-Barral, 2005) constituye un testimonio lírico formidable de lo que fue la segunda mitad del siglo XX en España. Son contados los casos de escritores que consiguen ofrecer a su lector una panorámica histórica y artística de semejante envergadura y profundidad. Se trata de una poesía de consumo asequible y fluido, solo aparentemente sencilla. Destacan, entre sus ingredientes fundamentales, una extraordinaria precisión lingüística y un estilo dinámico y depurado, donde conviven, a partes iguales, originalidad e inteligencia. Su visión irónica del mundo, en ocasiones, informal y, por momentos, realmente divertida cuaja, también, en una actitud ética ejemplar e implacable, forjada -debe tenerse en cuenta- contra las condiciones objetivas más duras.

Nacido en el Oviedo de entreguerras en 1925 en el seno de una familia laica y liberal, cuando Ángel González cuenta apenas once años de edad, estalla la Guerra Civil. Los constantes bombardeos sobre la ciudad, la convivencia cotidiana con la muerte y el crimen -entre todos ellos, y muy en especial, el asesinato de su hermano Manolo-, así como la represión económica y moral que el régimen fascista impone en la sociedad española desde 1939, lo alcanzan 
determinando estrechamente su vida. El recuerdo de aquellos años difíciles y las consecuencias, ya inmediatas o profundas, que de ellos se derivan nunca abandonarán al escritor; vuelven a su literatura con insistencia, de una manera recurrente y obsesiva, como si fuera necesario rescatar de ellos algo importante perdido entonces, como si fuera preciso sacarlo a la luz de la memoria para poder finalmente comprenderlo y explicarlo: "Jugabas entre muerte -confiesa el poeta-. / Creías que los muertos / eran objetos rotos / que alguien había tirado en las aceras. / Eras la vida pura / que lo ignora todo".

La trayectoria poética de Ángel González entre 1956 y 1967 presenta a su lector un proceso fascinante de afirmación existencial e ideológica en medio de un entorno que lo excluye, que no comprende y con el que, ya en su primer libro, entra en contradicción. Al paso de los años y llegado a su madurez humana y literaria, el poeta ha descubierto ya a su alrededor el país subdesarrollado y corrupto que era España durante la dictadura, aislado de todo lo que significaba entonces progreso y modernidad, sometido a una oligarquía y a un clero autocomplacientes que nada perdonaban ni consentían poco más allá de su rígida doctrina: "una patria sombría e inclemente", escribía en 1962 recordando la muerte de Antonio Machado. Desde entonces, el poeta asturiano se incorpora a una estética crítica y conflictiva, capaz de cuestionar la escala axiológica de valores - nacional, tradicional y católica- esencial del franquismo. Frente a la estilización amanerada, la evasión de la realidad y el misticismo que promovían los intelectuales afines al régimen, desde los primeros años cincuenta, lentamente y no sin serias complicaciones, los poetas españoles más conscientes comienzan a dar vida a un lenguaje realista, perfilan una voluntad inequívoca de identificación con los problemas del hombre español contemporáneo al que, a través de sus textos, prestan voz y dignifican. No siempre bien comprendida, la poesía social de posguerra fue un movimiento vivo, diverso en sus timbres y en sus expectativas, de amplios márgenes ideológicos y estéticos —desde Gabriel Celaya hasta Jaime Gil de Biedma, o desde un Gabino-Alejandro Carriedo hasta un José-Miguel Ullán-, alcanzando verdaderas cumbres de sensibilidad, de humanismo y de acierto, en la obra poética de Ángel González y sus compañeros de la llamada Promoción del 50.

El presente cuestionario ha querido iluminar la opinión del poeta sobre esa área de creación comprendida entre 1939 y el medio siglo, un periodo de formación clave en el que Ángel González forja su personalidad como escritor modelando, palabra sobre palabra, lo que será uno de los rasgos que definen positivamente al conjunto de su literatura: la poderosa interacción establecida entre el poeta y el paso del tiempo. La historia podrá, ciertamente, estar escrita por quienes vencen; y es esa una realidad nítida e incuestionable, bien conocida por los cientos de miles de españoles exiliados o represaliados por el régimen. 
Sin embargo, también a veces los derrotados encuentran un tiempo y un espacio -aun breves o imaginarios como el de un poema- donde conjurar a sus fantasmas y al fin, como en un pronóstico exacto del futuro, reconciliarse con el pasado:

Los vencedores

tras recibir entre ovaciones, besos y banderas,

coronas de laurel, medallas, cigarrillos, estrellas de latón, botín y gloria,

oyeron

al fin de la jornada

una última orden inflexible:

arrojar las armas

romper filas en calma y en silencio, dispersarse.

La Victoria había sido un error del alto mando, menos

tal vez que una ilusión

-acaso una traición o una mentira.

Su sueño heroico, sus himnos,

su grandeza,

su imperio de humo y sangre,

quedaban abolidos,

teñidos de ignominia por decreto.

Algunos

jamás llegaron a saberlo.

Y la borrosa duda sugerida

por sus ojos abiertos y asombrados

no llegó a desvirtuar esa sonrisa

insolente, distante, dura, helada

para siempre en sus labios

por el rictus amargo de la muerte.

(Poema “Divagación onírica”)

\section{CUestionario}

Pregunta: En 1939, la práctica totalidad de los profesionales de la cultura se encontraban muertos, en la cárcel o marchaban al exilio. En medio de ese vacío, comienzan a aparecer pequeños núcleos poéticos y plataformas 
en las provincias como reacción al modelo formalista oficial del estilo de Proel, Cordel o Espadaña. ¿Cómo valora la labor de estas revistas poéticas de la inmediata posguerra?

Ángel González: Jugaron un papel muy importante. Proel, por ejemplo, fue una revista que publicaba cosas que estaban incluso prohibidas. Creo que fue Proel la que publicó por primera vez un artículo de Sartre, que se llamaba "El marxismo es un humanismo", fue la primera cosa de Sartre y la primera vez que apareció el nombre del marxismo de una manera productiva en una revista. Yo creo que fue Proel; no estoy seguro pero creo que fue una de esas revistas. Crearon una gran labor; una gran labor de recuperar algunos nombres, los que podían, proscritos o exiliados, nombres olvidados. Sí, fue una labor muy importante.

P: Toda la crítica atribuye a Sombra del paraíso de Vicente Aleixandre y a Hijos de la Ira de Dámaso Alonso, haber iniciado un nuevo camino para la poesía española de la posguerra marcado por la humanización y el anti-formalismo. ¿Qué importancia cree que tuvo la publicación de ambos volúmenes?

AG: En efecto, se dice siempre que fueron muy importantes esos libros y es verdad. En todo caso, el libro de Dámaso Alonso era un libro religioso; aunque señalaba un mundo defectuoso, un mundo injusto, un mundo cruel, cosa que se correspondía muy bien con la realidad de la posguerra. El libro de Vicente Aleixandre era lo contrario. No sólo era anti-formalismo, creo yo -que lo era-, que reaccionaba contra aquella "primavera del endecasílabo", así llamada; era también la nostalgia de un mundo bello, perfecto y laico, al contrario que el libro de Dámaso Alonso que era un libro religioso y apesadumbrado. Este era un libro con una visión luminosa y esperanzadora sobre una especie de paraíso que estaba antes, antes de la guerra.

Yo creo que el libro que más influyó o los libros que más rompieron, fueron Los poemas de Juan de Leceta de Gabriel Celaya y Alegría de José Hierro. Son los libros que rompen el esquema; rompen formalmente anticipando el lenguaje que ya iba a usar la generación del cincuenta. Juan de Leceta hace un lenguaje urbano, no un lenguaje castizo como puede ser, por ejemplo, el de Claudio Rodríguez, sino un lenguaje urbano, civilizado, de un burgués medio y culto, que reflexiona sobre las cosas cotidianas. Fue un descubrimiento muy importante para mi generación. Por otra parte, Hierro, frente al tono un poco quejumbroso y melancólico de los poetas de Garcilaso, publica libros, Alegría fundamentalmente -quizá porque es el que yo lo leí primero en aquellos años-, en donde afirma la necesidad de alegría en tiempos difíciles, en tiempos malos. 
Hierro dice alegría por que la circunstancia era propicia, él sabe, él lo dice: hemos estados solos, hemos tenido frío, hemos estado solos entre cuatro paredes, sin embargo, alegría; hay que recuperar la alegría en medio del desastre. Creo que esos libros, los de Leceta y el de Hierro, en lo que a la poesía se refiere, supusieron una novedad importante, tal vez con más trascendencia que los de Dámaso y los de Aleixandre, aunque ellos hicieron más ruido, esa es la verdad, fueron más leídos, más comentados. La percepción de que esos libros rompieron el esquema es verdadera, pero también hay que añadir, creo yo, libros muy importantes como Tranquilamente hablando que ya es toda una tesis de Juan de Leceta, supone todo un programa de actuación poética. Y lo mismo Alegría.

P: A comienzos de la década de 1950, entre los poetas inmediatamente previos a su generación, comienza a extenderse el movimiento conocido como la poesía social, un paradigma creativo con el que se ha relacionado su obra. ¿Qué causas cree que motivaron el nacimiento del fenómeno y cuál es a su juicio el significado de la poesía social en el marco de la dictadura franquista?

AG: La llamada poesía social estuvo justificada por la dictadura y la Guerra Civil. Pero no sólo eso; sino que recogía una línea estética que había estado muy presente en la poesía española hasta mediados de 1936, una poesía de trasfondo claramente político como la de Alberti por ejemplo; esa poesía estaba tomando gran presencia por ejemplo en el último Miguel Hernández; en el primero no, que era un poeta católico y muy conservador, pero en el último Miguel Hernández era una línea muy marcada. Y no sólo era Alberti, también Juan Gil-Albert en un momento determinado. Esa línea fue, claro, interrumpida por la guerra y la inmediata posguerra. En cuanto pasó un poco de tiempo, no mucho, algunos poetas sobre todo poetas que por edad podían estar en la generación del 36 como Celaya, por ejemplo, y Victoriano Crémer en León, Eugenio de Nora y José Hierro, recuperaron esa línea rota por la Guerra Civil. De manera que fue una especie de normalización, de enganche con el pasado también. Fue, desde luego una poesía surgida de las necesidades propias del momento, de la necesidad de denunciar a la dictadura. Fue una poesía espontánea y natural. En algunos momentos, sobre todo en la primera etapa, estaba detrás el Partido Comunista desde luego, pero no en todos.

Eso fue la justificación de la poesía social; era necesaria esa poesía; era necesaria esa literatura frente al conformismo y al edulcoramiento de la poesía dominante y protegida. Luego llegó mi generación, que de una manera distinta se planteó los mismos o muy parecidos objetivos. Era la hora del llamado realismo crítico, que prolonga de otra manera la poesía social. 
P: En un artículo del año 1955, frente a la poesía entendida como comunicación cultivada por los autores de la primera generación de posguerra, Carlos Barral planteaba la alternativa de una poesía entendida como conocimiento, ¿cómo considera que afectó la controversia al diálogo entre las dos generaciones de posguerra y a la actitud social comprometida?

AG: El conocimiento hace más complejo el compromiso, creo yo. Esa polémica, sí, fue muy viva cuando éramos jóvenes. Carlos Barral participó en ella, Ángel Valente y algunos más. Fue Vicente Aleixandre quien dijo “La poesía es comunicación" y esa afirmación de Aleixandre fue contestada por Carlos Barral. Eran matices que yo creo que no aclaraban demasiado las cosas, porque la poesía es conocimiento y es comunicación. La poesía es todo eso y más. No se puede excluir la parte de comunicación que hay en la poesía, ni se puede negar que la poesía debe ser y es una forma de investigar, de conocer el mundo y la realidad, incluso socio-política. La concepción de la poesía como conocimiento no excluía creo yo la integración de la poesía en la historia.

P: En la antología Veinte años de poesía española el crítico José María Castellet identificaba una evolución homogénea de los autores españoles desde la actitud y la expresión simbolistas hacia el realismo, una estética que vendría a culminarse plenamente en la obra de su generación cronológica. ¿Cree que podría establecerse una relación entre la poesía social y la estética realista?

AG: Se puede establecer una relación entre la poesía social y el realismo en cuanto a que los motivos eran parecidos: denuncia, lucha contra la dictadura. Prueba de ello es la Colección Colliure, que era una colección ideada por Carlos Barral que constaba de doce números. Una colección que Carlos, que ya estaba en la editorial Seix-Barral, pensó como un experimento para intentar que la poesía se vendiese como un libro más, como un libro; aquellas tiradas, por ejemplo de Adonais, que eran de setecientos ejemplares... él quería hacer unas tiradas dignas de mil quinientos o dos mil ejemplares, y distribuirlas como se distribuye una novela. Eso por una parte. Por otra parte, era una forma de presentarnos como grupo. Entonces en esa lista de doce ejemplares, de doce autores, Carlos Barral incluyó dos poetas de la generación anterior que eran Gabriel Celaya y Blas de Otero. Blas de Otero creo que no llegó a publicar su libro, pero Gabriel Celaya sí publicó, precisamente Los poemas de Juan de Leceta; mejor dicho, los reeditó, porque ya estaban publicados con anterioridad. Eso demuestra que Carlos Barral veía en ellos un origen, un vínculo, y que estábamos relacionados con esos poetas. Y, aunque las maneras de abordar los 
temas y los problemas sociales eran muy distintas y enfocábamos de manera distinta la temática llamada social a la de Celaya o la de Blas de Otero, ellos eran un primer antecedente para la poesía de tono realista y crítico surgida después de la Guerra Civil.

P: Usted ha señalado que se inicia en la poesía a una edad razonablemente adulta. De hecho, su primer libro Áspero mundo pone de relieve una estética compleja que revela un grado alto de precisión lingüística y de solidez compositiva. ¿Cuáles son los motivos que le llevan a escribir y a publicar poesía?

AG: Bueno, yo tardé mucho en decidirme a publicar. Había escrito bastante, con bastante asiduidad desde los dieciocho años, pero no escribía con ánimo de publicar. No me atrevía a pensar que aquello pudiese ser una poesía digna de atención de los demás. Escribía un poco por desahogo personal. Algunos de esos poemas, muy influidos por el Juan Ramón Jiménez de la Segunda antolojía, por Lorca, por Alberti... poemas muy estetizantes, muy formalistas, sonetos, canciones, etcétera, algunos de esos poemas los recuperé. Luego escribí una serie de poemas más testimoniales, recogidos en la primera parte del libro "Áspero mundo". Yo pensaba entonces que esos testimonios, ese hablar de mí y de lo que me estaba pasando, pues podía tener más interés para un lector que un soneto a Danae. Y así armé el libro, con esos dos elementos; sin tener ninguna conciencia de lo que era la poesía crítica, social o histórica. Yo había estado mucho tiempo solo y había escrito una poesía, no anacrónica porque estaba próxima, pero que no era lo que se estaba haciendo entonces: la Generación del 27, Juan Ramón Jiménez... Cuando ya me reincorporé a la vida normal, salí de aquel pueblo de León y fui a Oviedo a estudiar, entonces comencé a leer otros poetas: a José Hierro y su libro Alegría, a Gabriel Celaya y a otros poetas americanos como Vallejo que yo no conocía. Poetas americanos había leído a Rubén Darío y al primer Neruda, el de los Veinte poemas de amor, que era lo único que podía circular por España.

Hay algo que siempre digo en mis lecturas, es una idea muy repetida por mí que, al publicar los poemas testimoniales, cuando los vi impresos, me di cuenta que en mí había un desaliento y un sentimiento de derrota y de fracaso que yo no sabía a qué se debía; no reconocía en mí a ese personaje fracasado, desolado. Luego me di cuenta a que se debía: a la Guerra Civil. No era una derrota personal, sino una derrota colectiva la que me movía, la que despertaba en mí ese sentimiento. Es entonces cuando de una manera deliberada, o mejor dicho, de una manera consciente, comienzo a hacer una poesía de tono crítico, histórico y social. En Áspero mundo aparecen algunos rasgos que se pueden emparentar con la poesía social y crítica, pero esos rasgos eran por mi parte 
completamente inconscientes; no era consciente de que aquello tenía un sentido críptico. Es en Sin esperanza, con convencimiento cuando yo empiezo a tratar el tema de la historia y de mi historia con una intención crítica.

P: ¿Cómo llegó a plantearse de una manera consciente la realidad histórica de lo que estaba sucediendo a su alrededor y a adoptar ese compromiso político?

AG: Tomar conciencia de la Guerra Civil fue en mí un proceso completamente natural y espontáneo; no necesité ningún tipo de reflexión. Mi padre había sido republicano declarado y además ateo, para mayor escándalo de la ciudad de Oviedo. Era profesor de pedagogía y tenía sus teorías personales; yo creo que quería casi predicar con el ejemplo, demostrar que no hacía falta creer en un dios trascendente que nos premia y nos castiga para llevar una vida absolutamente ética. Él murió cuando yo tenía dieciocho meses, pero dejó en casa la semilla del republicanismo y de una ética civil, no religiosa. Muy madre sí era muy religiosa pero quiso y supo transmitirnos, y transmitirme a mí, las ideas de mi padre. De manera que mis hermanos, mayores que yo, estaban muy politizados. Uno pertenecía al Partido Socialista; el otro no, estudiaba ingeniería y era un hombre de ideas incluso más radicales, pero no estaba implicado en ninguna actividad realmente política, era simplemente un hombre con ideas. Y todo eso salía en la mesa. Mi hermano mayor, el ingeniero, era más radical que mi otro hermano, estaba más cerca del comunismo; mi otro hermano, como socialista, no simpatizaba para nada con ese mundo; entonces ellos discutían en la mesa y yo oía discusiones. Incluso mi hermana que era maestra también estaba muy interesada en la política. Ese republicanismo nos marcó a todos; se leían muchos periódicos en casa, mucha prensa, me acuerdo de Crónica por ejemplo, incluso se compraba prensa de Madrid. Todo eso yo lo viví de niño y se fue metiendo en mí.

Luego, cuando estalló la guerra, aquello ya era muy evidente. No era sólo leer periódicos. Bueno, y antes la Revolución del 34, en la que uno de mis hermanos, el socialista, participó y se tuvo que exiliar. Todo eso fue creando en mi una mentalidad, una conciencia de que la política y las luchas reivindicatorias eran algo que merecía la pena e importante. Cuando estalló la guerra, cuando vino aquel desastre, para mi familia tremendo, entonces ya no hacía falta teorizar mucho para darse cuenta de las cosas. Así que de una manera natural yo me fui educando cívicamente.

P: A través del personaje de "el derrotado" de su segundo libro Sin esperanza, con convencimiento toman ya forma en sus textos algunos contenidos críticos como el tema de la Guerra Civil, la relación entre los 
vencedores y los vencidos o denuncia a la estructura social y política del régimen franquista. ¿Qué papel atribuye a la memoria de la guerra en ese libro?

AG: Pienso que la relación de mi poesía con la memoria de la Guerra Civil es muy directa. Se habla a menudo de los niños de la guerra pero eso no dice nada, creo yo. Todos fuimos niños de la guerra tanto los que colaboraban en la revista Garcilaso como los que estábamos fuera de ese grupo. La manera de vivir la guerra civil fue muy diferente en todos nosotros. Creo que fui el único, quizás haya alguno más, que vivió la guerra en un campo de batalla de verdad; Oviedo fue un campo de batalla durante casi dos años; desde casa veía las trincheras, estaba en primera línea de fuego; nos obligaban a salir de casa para abajo, a la calle, porque aquello ya iba a estallar. Esa vivencia de la guerra en pleno campo de batalla por una parte y por otra parte mi familia. La familia de casi todos mis compañeros que luego fueron poetas críticos muy politizados como Jaime Gil de Biedma por ejemplo, Carlos Barral o Caballero Bonald, eran familias de la alta burguesía muy confortablemente instalados en el nuevo régimen, con ideas muy conservadoras; ellos sí tuvieron que tener un proceso intelectual muy duro para darse cuenta de lo que estaba ocurriendo y del sentido de las cosas. Pero en mí fue un proceso natural. De manera que el recuerdo de la guerra estaba en mí muy vivo; no tuve que inventar nada, en mi caso, ni recordar porque estaba tan vivo que para mí era el presente histórico, a pesar de que la guerra ya había terminado.

En Sin esperanza, con convencimiento tengo dos poemas sobre la guerra uno que se llama "El campo de batalla" y otro "Entreacto". Yo tenía la conciencia de que la Guerra Civil había terminado con una victoria, pero que ese final no representaba el fin real de la Guerra Civil, que iba a resolverse de otra manera en un momento determinado, que iban a pasar otras cosas, que iba a haber otro final. Por eso acudí a correlatos objetivos, al entreacto, o a describir el campo de batalla completamente en abstracto, donde también hay un final en que los hombres esperan no se sabe qué. Yo tenía esa idea de que el final de la Guerra Civil no era el definitivo y eso lo expresé en esos poemas de Sin esperanza, con convencimiento.

P: En torno al año 1958, establece usted los primeros contactos con el Partido Comunista de España, organización en la que militó durante casi una década. ¿Qué papel opina que jugaron el PCE y el pensamiento marxista entre los intelectuales españoles de los años 50 y 60 ?

AG: En mi generación, casi todos los que estábamos en desacuerdo con la dictadura de una manera clara, nos acercamos al Partido Comunista, que era 
entonces, con todos sus errores y defectos, la fuerza más eficaz. La única fuerza realmente organizada contra la dictadura era el Partido Comunista. El Partido Socialista tenía una presencia mucho más vaporosa, mucho menor, luego adquirió fuerza y presencia, pero entonces el partido que proponía y que estaba organizado dentro era el comunista; las cárceles estaban llenas de comunistas. Si uno quería hacer algo medianamente eficaz contra la dictadura pues el Partido Comunista era la vía de entrada. En cuanto al marxismo, yo no creo que, salvo excepciones, fuera una teoría que conociéramos muy bien, la conocíamos por aproximación, las cosas básicas; marxólogos no creo que hubiera muchos en mi generación. Sí teníamos una idea de lo que era la filosofía de Carlos Marx, pero la influencia del marxismo en nuestra obra fue muy poca.

\section{P: ¿Cómo valora la recepción de autores como Jean-Paul Sartre, Bertolt Brecht o George Lukács?}

AG: Llegaban muy mal por la censura; tal vez algunos ejemplares, algunos libros, pero muy pocos. El libro famoso de Sartre ¿Qué es la literatura?, donde expresa su idea del compromiso, ese libro sí creo que lo leímos todos, pero poco más. Tal vez Lucáks algo más tarde. Era muy difícil conseguir esos libros.

P: Desde el punto de vista del compromiso, ¿cómo cree que afectó la censura a la poesía del periodo?

AG: Lo primero que hizo la censura fue meternos un censor dentro a cada uno de nosotros. El primer censor era el autor. Al escribir, jugabas con las posibilidades de llegar hasta el último límite que la censura podía tolerar. Muchas veces nos pasábamos de los criterios tan cerrados de la censura y hubo libros que tuvieron graves problemas. Por ejemplo, la obra de Jaime Gil que fue objeto de muchas conversaciones por parte de Carlos Barral, que era el editor, con el Ministerio de Información, y que al fin fue guillotinada. Sí, influyó. Y algunos dicen que consiguió que el lenguaje poético, que la expresión fuera más sofisticada; puesto que no se podían decir las cosas directamente, teníamos que recurrir a procedimientos sofisticados como el correlato objetivo, la ironía, etcétera.

P: En concreto, la ironía ha sido señalado como un procedimiento característico de su poesía, ¿qué papel juega ese recurso, los hablantes irónicos, en sus versos? 
AG: La ironía fue, en principio, una herramienta para poder decir las cosas que el censor no permitía decir, pero luego la ironía fue para mí una especie de modelo del mundo. La realidad es ambigua en sí misma, contradictoria; para expresar esa ambigüedad de la realidad la ironía es el único modo, el único procedimiento que lo permite.

P: Su tercer volumen, Grado elemental, puede ser considerado uno de los más políticos de toda su obra. Lo publica usted en Francia, en la editorial Ruedo Ibérico, una plataforma muy ideológica, que le valió el Premio Antonio Machado de poesía en 1962. ¿Cómo cree que influyó esa circunstancia en la confección de Grado elemental?

AG: En la dictadura, llegó un momento, aunque tardó en llegar, en que podíamos adquirir pasaportes y que ir a París no era tan difícil. Con Ruedo Ibérico manteníamos relación y los libros de Ruedo Ibérico, no sé cómo, llegaban. Cuando se convocó el Premio Antonio Machado, que se convocó esa vez por única vez, yo estaba escribiendo poemas, el resto los escribí de una manera más desinhibida, sabiendo el tono y las intenciones de la editorial.

Sí, Grado elemental es el más político de toda mi obra; es el único libro que tiene sólo poemas de tono crítico e histórico; en los demás mezclo poemas sobre el paso del tiempo o el amor. Ese libro lo monté con poemas que ya tenía y con algunos que escribí entonces, ya digo, de una manera más desinhibida. Finalmente, tuve la suerte de ganar el premio, lo que permitió la publicación del libro, un libro que en España no hubiera podido salir. Cuando lo quise incorporar a la poesía completa años después me quitaron cuatro poemas.

P: Su cuarta entrega, Palabra sobre palabra, constituye un libro de temática amorosa, una de las más reconocidas y habituales entre todas las suyas. ¿Cómo diría que se relacionan en sus composiciones del periodo el tema del amor y la estética del realismo? ¿Qué papel juega la tradición en sus versos de amor de la posguerra?

AG: Casi todos mis poemas de amor responden a vivencias reales, a vivencias concretas, a historias vividas. Algunas son inventadas, pero la mayoría no. La mayoría responden a problemas o vivencias verdaderas; son una expresión en cierto modo realista de lo que yo estaba viviendo. En Áspero mundo, por ejemplo, hay poemas que son absolutamente literarios sobre el amor y otros no. Hay una sección que se llama "Acariciado mundo" que está escrita pensando en una persona concreta, aunque no cuento ninguna historia; es una imaginación de esa persona iluminando o transformando de alguna manera el mundo. Yo no era entonces consciente de estar en ninguna tradición; pero 
estaba evidentemente. Las lecturas que yo había hecho me habían influido, pero yo no era consciente de estar en tradición alguna. En algunos sonetos o canciones sabía que estaba en alguna tradición de los cancioneros que leí entonces y que releí después en poetas como Alberti, como Lorca o como el propio Machado que tiene muchas formas cancioneriles y de canción que él actualiza; era consciente de que estaba en la línea de algunos de esos poemas.

\section{P: ¿Cómo influyó en su poesía escrita durante la dictadura la obra de los autores exiliados?}

AG: La verdad es que entonces no conocíamos bien la obra del exilio y tardamos mucho en conocerla. Había una enorme incomunicación y una censura muy fuerte. De manera que no conocíamos lo que se estaba haciendo... la gran sorpresa que por ejemplo para un hombre como Jaime Gil de Biedma supuso el descubrimiento de Luis Cernuda. No, no sabíamos lo que se estaba cociendo en la otra parte, tardamos mucho en conocer la obra escrita en el exilio de Cernuda o de Alberti, por ejemplo. Tardamos mucho.

P: Tratado de urbanismo, el último de los volúmenes integrados en su obra social, muestra una crisis muy intensa en la eficacia de la palabra poética. Sin embargo, es posible apreciar también una denuncia muy nítida a la sociedad burguesa y al sistema económico y político del momento. ¿Cómo diría que se relacionan en ese libro el compromiso y la poesía social?

AG: Creo que en ese libro está el poema "Preámbulo a un silencio". Es un poema que está escrito a lo largo de bastante tiempo. Jaime Gil de Biedma tiene algunas reflexiones sobre cómo influye el tiempo en los poetas lentos como él, que se reconoce un poeta de escritura lenta y cómo el tiempo influye metiendo en el libro una parte importante de la historia del autor. Tratado de urbanismo está escrito en dos momentos distintos; un momento en que yo seguía lo mismo que en los libros anteriores y luego en otro de una pérdida de fe, un desánimo. La dictadura había durado demasiado, parecía que no había nada que hacer frente a ella y que en cierto modo estábamos como perdiendo el tiempo; el régimen había sobrevivido a todas sus crisis exteriores e interiores y estaba más fuerte que nunca. Ese momento de desánimo que se expresa en "Preámbulo a un silencio" se debe a eso. En mi caso quizá se produjo una fatiga. Pero fue, siempre lo digo, un momento de desánimo pasajero. La poesía aunque no sea capaz de derribar un régimen, desde luego, no deja de transformar el mundo; un poema puede cambiar nuestra manera de ver las cosas; el mundo, en efecto, es tal y como lo vemos, es tal y como lo percibimos, y si un poema altera 
nuestra percepción del mundo y lo vemos de forma diferente, el mundo queda de alguna manera alterado.

P: Ya para terminar, con la perspectiva del tiempo, ¿cree que el compromiso social que adoptó durante los años de la dictadura mantiene vivo hoy su significado?

AG: En mi último libro Otoños y otras luces aparecen algunos poemas que vuelven a la historia, al pasado, al recuerdo de aquellos años. Y creo que el compromiso se mantiene; lo está haciendo, creo yo, de otra manera. Poetas más jóvenes que yo, como por ejemplo Luís García Montero, abordan temas éticos, en cierto modo, muy relacionados con la política. 